\title{
Multicódigos Reabituantes
}

\author{
Eduardo Fernandes Araújo
}

PIMENTA, F. J. P.

Ambientes multicódigos, efetividade comunicacional e pensamento mutante.

São Leopoldo, RS: Editora

Unisinos, p.196, 2016.

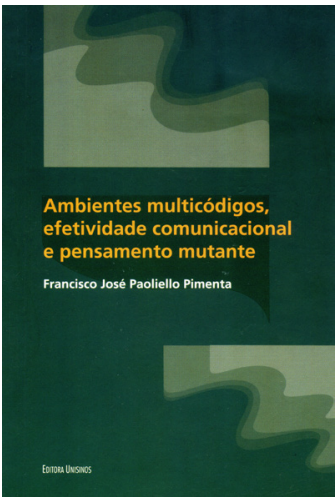

Resumo: Como processos comunicativos alcançam maior efetividade comunicacional? Ambientes multicódigos promovem vínculos linguagem/tecnologia e vínculos linguagem/tecnologia promovem transformações cognitivas. Logo, ambientes multicódigos promovem transformações cognitivas (pensamento mutante). Inspirada nesse raciocínio, a pesquisa sobre ambientes multicódigos mostra que a efetividade comunicacional nasce da tomada de consciência estimulada por mudanças de hábitos, mediante práticas que se utilizam das redes digitais multicódigos. O livro aborda como objeto empírico grupos de ciberativistas, usuários de videojogos e epistemólogos da comunicação. Os resultados apontam para outra hipótese acerca do novo objeto epistemológico da comunicologia: o processo de produção de referências aderentes à dinâmica do real, conduzindo os agentes nela imersos a reabituações do entendimento em seu sentir/agir/pensar. O objetivo é destacar as contribuições da semiótica pragmaticista de Charles S. Peirce como saída para a crise epistemológica da comunicação, sugerindo preciosas abduções e analogias com os atuais desenvolvimentos da biossemiótica.

Palavras chave: comunicologia; epistemologia; multicódigo; reabituação; biossemiótica.

Abstract: Habit-changing multicodes - How do communicative processes achieve communicational effectiveness? Multicode environments promote language/technology binds, and binds of language/technology promote cognitive changes; thus, showing that multicode environments promote cognitive changes (mutant thinking). Inspired by that reasoning, the research 
on multicode environments shows that the communicational effectiveness is born from consciousness-taking stimulated by changes of habit using multicode digital networks. It approaches as its empirical object those groups of cyberactivists, video game players, and epistemologists of communication. The outcomes point out to another hypothesis about the new epistemological object of communicology: the production process of references linked to the dynamics of the real addressing the agents herein encompassed to habit-changings of understanding in their own way of feeling/acting/thinking. The aim is to draw the contributions of Charles S. Peirce's pragmaticist semiotics as an output of the communication's epistemological crisis by suggesting important abductions and analogies with the today's developments of biosemiotics.

Keywords: communicology; epistemology; multicode; habit-changing; biosemiotics.

A obra Ambientes multicódigos, efetividade comunicacional e pensamento mutante parte da intuição de que as tecnologias digitais em redes multicódigos influenciam nossos modos de comunicação e pensamento (e, portanto, nossos modos de conduta perante a vida daí resultantes). Como interações afetam e são afetadas por tecnologias em rede multicódigo? Como se dá a aprendizagem colaborativa, do acaso ao hábito? Como tais modos de interpretação e aprendizagem estimulam e garantem maior efetividade no comunicar? Em suma: como processos comunicativos alcançam maior efetividade comunicacional? Eis a pergunta da pesquisa.

A primeira hipótese, como resposta à questão, é que a comunicação multicódigo por rede digital estimula a geração de pensamentos em transformação que promovem maior efetividade da comunicação. Há no livro, do meio para o final, a extração de uma segunda e mais ampla hipótese, à qual voltaremos mais adiante, e se refere aos debates sobre a nova epistemologia da comunicação em sua relação com a biossemiótica. O livro foi dividido em seis capítulos (enriquecidos com detalhados 29 diagramas que ilustram e didatizam as explanações); cujo tratamento da argumentação tem sua fundamentação na filosofia pragmaticista de Charles $\mathrm{S}$. Peirce.

No primeiro capítulo, A mudança de hábitos explicada pela máxima pragmática, Pimenta introduz os princípios da conhecida máxima pragmática de Charles S. Peirce: 1) o conceito de um objeto é o conjunto de todas as suas consequências práticas que podemos conceber/imaginar; 2) o significado completo de um conceito/concepção é a soma das consequências que necessariamente resultam da verdade dessa concepção; 3) o hábito geral que produz os efeitos de um objeto é o significado total de seu conceito (o hábito mental geral consiste no próprio processo de produção desses efeitos). Logo, o hábito mental não é resultado do conceito, mas o processo mesmo de produção dos resultados do conceito. O significado de um conceito é, portanto, a mudança de hábito derivada da investigação.

Assim entendida, a máxima pragmática nos leva às três proposições cortantes (no sentido da navalha de Ockham) estabelecidas por Peirce: a) nada chega a ser 
intelecto sem antes atravessar os sentidos/percepções (Aristóteles); b) se premissas (juízos perceptivos) contêm termos gerais, então conclusões (proposições generalizantes) podem ser delas inferidas; c) hipótese é a ideia de reunir o que nunca antes fora associado, lampejando novo entendimento do que contemplamos com surpresa.

Hipóteses devem ser montadas na forma argumental de desenhos relacionais (grafos existenciais) a fim de observarmos até onde a elasticidade da hipótese é mesmo uma inferência previsível aderente ao fenômeno surpreendente. Daqui em diante, explica porque a abdução, na perspectiva peirceana, deve andar sempre de mãos dadas com a dedução e a indução. A dedução, em seguida, vai perguntar ao diagrama abduzido: há padrões de efeitos gerados pela concepção do objeto? Qual a melhor contribuição desta hipótese como previsão dos padrões de efeitos do objeto assim concebido? Se a hipótese for verdadeira, quais suas necessárias consequências práticas? Para validar ou não a verdade de tais consequências aqui deduzidas, o diagrama deve ser submetido aos testes da indução com amostras do contexto existencial sob investigação (diagramas 1 a 4 do livro).

No segundo capítulo, A hipótese sígnica do pensamento mutante pela comunicação multicódigo, o autor resgata os embasamentos teóricos para sua primeira hipótese de pesquisa, acerca dos ambientes multicódigos que promovem reabituações cognitivas. O ciclo completo abdução-dedução-indução nos traz à seguinte preocupação: enfim, qual é o princípio-guia que governa os processos comunicacionais? Como se dá a tomada de consciência pela experiência do comunicar?

A etapa abdutiva elabora então a seguinte linha de raciocínio: 1) eis algo (signo) + há algo (objeto dinâmico) = percebo algo (juízo perceptivo); 2) percebo algo + há mesmo algo = há este algo (objeto imediato); 3) percebo algo + há este algo = há outro(s) algo(s) assim no universo? (argumento abdutivo). Traduzindo: 1) eis multicódigo + há mudança = percebo (mudança pelo) multicódigo; 2) percebo multicódigo + há mesmo mudança = há esta mudança (por multicódigo); 3) percebo multicódigos + há estas mudanças = há outras mudanças por multicódigos que ocorrem no universo sob este mesmo princípio-guia?

A etapa seguinte é dedutiva, e busca extrair necessariamente quais consequências práticas se pode esperar ou prever (as três sub-hipóteses), caso o padrão de efeitos diagramado na abdução se prove verdadeiro: 1) efeitos práticos estéticos: representações sinestésicas e sensação de compartilhamento; 2) efeitos práticos éticos: representações presenciais e engajamento coletivo; 3) efeitos práticos lógicos: representações reabituantes e autoconsciência inferencial. A etapa derradeira do ciclo é indutiva, e consiste em planejar e recortar bem o objeto empírico que será submetido a teste: 1) como detectar características de compartilhamento entre ciberativistas, videojogadores e epistemólogos; 2) como detectar características de coletivismo entre ciberativistas, videojogadores e epistemólogos; 3) como detectar características de autoconscientização entre ciberativistas, videojogadores e epistemólogos. Posta nessa forma, a pesquisa pode controlar as variáveis e invariáveis da hipótese e, por fim, afirmar a medida de falibilidade do que foi abduzido: 
"nossa hipótese é ou não verdadeira" (= aderente à dinâmica do real)? "Nossa hipótese pode ser reajustada, ou deve ser reformulada"? (diagramas 5 a 15 do livro).

No terceiro capítulo, Os processos comunicacionais dos usuários das redes multicódigos, descreve e analisa detalhadamente os nove grupos de usuários de redes sociais em suas práticas discursivas cotidianas, três de ciberativistas (EuroMayDay, Zapatistas e Wikileaks), três de videojogadores (SecondLife/Kaneva, Metaversos e World of Warcraft), e três de epistemólogos (GT-Epistemologia/COMPÓS, Transformática e UNISINOS).

Com base nos critérios de efeitos práticos estabelecidos dedutivamente, o teste indutivo verificou, para cada grupo empírico analisado, o grau de confirmação das três sub-hipóteses. Além desse recorte empírico, resultados semelhantes aos acima apresentados foram obtidos em outras investigações realizadas por Pimenta no âmbito da pesquisa acerca dos ambientes imersivos e redes sociais para disseminar mudanças cognitivas e processos comunicacionais (diagramas 16 a 25 do livro).

No quarto capítulo, Redes multicódigos, mudança de hábito e o campo da comunicação, enceta comentários acerca dos resultados obtidos pelo tratamento da primeira hipótese do autor mediante o ciclo abdução-dedução-indução. O capítulo ressalta as vantagens do realismo pragmaticista quando comparado ao tradicional nominalismo estruturalista da comunicologia até então: tanto o nominalismo antrópico (homem como produto de meio cultural), quanto o nominalismo historial (verdade como relativa a cada fase cronológica), como o nominalismo individualista (a verdade é sempre relativa a cada indivíduo). A partir daqui, passa a insinuar o desdobramento da segunda hipótese oriunda desta investigação, conforme o ponto de vista do pensamento pragmaticista: a razoabilidade do universo engloba todos os processos comunicacionais, no humano como na natureza vivente e, quiçá, também abiótica.

A segunda hipótese começa a ser construída: a semiótica pragmaticista lida com a razoabilidade do universo para descrever e conhecer as etapas por meio das quais a mente-matéria adquire conhecimento e muda de hábitos, reconstituindo suas próprias leis físicas. Nesse contexto, passa a ver os fluxos comunicacionais como uma subclasse dos processos mesmos de produção de conhecimento, dado que a comunicação é a biografia da mente-matéria em contínuo devir de compartilhamento, coletivismo e autoconscientização. Encerra o capítulo oferecendo exemplos dessa nova concepção do conceito de comunicação ao referenciar diálogos de pesquisa com outras áreas: jornalismo, cibercultura, sociologia, epistemologia e biologia (diagramas 26 a 29 do livro).

No quinto capítulo, O pensamento mutante e a comunicação multicódigos, encontramos as considerações finais desta pesquisa, onde se destaca a importância da constante atenção ao falibilismo e à fragilidade de todo e qualquer processo científico abdução-dedução-indução, o que demanda contínua revisão e reconstituição, por uma comunidade de pesquisadores, do conhecimento já constituído. É preciso manter aderência às novas regularidades que surgem no real. 
Assim sendo, a eficiência comunicacional tem como objetivo a conduta deliberada e autocontrolada ou autocorretiva. A comunicologia seria definida como uma ciência ocupada com a promoção da mudança e da inovação. E este novo olhar epistemológico sugere, enfim, uma nova concepção do objeto de conhecimento da ciência da comunicação (segunda hipótese da pesquisa), qual seja: todos os processos de imaginação/criação/ produção de referências sígnicas aderentes a contextos existenciais, isto é, à dinâmica mesma do real, à razoabilidade do universo, de modo a conduzir os agentes nela imersos a reabituações de seu próprio sentir/agir/pensar.

No sexto capítulo, A comunicação como uma ciência da vida?, Pimenta oferece os novos fundamentos teóricos que justificam a segunda hipótese, a saber, as íntimas relações entre ciências comunicacionais e biológicas, chamando a atenção para os atuais desenvolvimentos da biossemiótica, desde seus primeiros teóricos no início do século XX, como Uexküll, Vernadsky, Tansley, Lótman e Sebeok, até os mais recentes na virada para o século XXI, como Kull, Deacon, Emmeche, Hoffmeyer e Stjernfelt.

A efetividade comunicacional em ambientes biossemióticos também se dá: 1) pela percepção de qualidades sígnicas do espaço compartilhado (dimensão estética), 2) pelo exercício de suas características existenciais para fins de comunicação desejável naquele ambiente (dimensão ética), 3) e pela demonstração de domínio articulador de linguagens com os processos da lógica natural de reabituações naquele ecossistema. Esse caráter evolutivo e generalizado consiste no summum bonum da biossemiótica.

Resumidamente: os processos de comunicação podem se tornar mais efetivos a partir das proposições do pragmaticismo peirceano. Os processos semióticos as semioses - não devem ser impedidos em seus fluxos que caracterizam as diversas etapas das múltiplas matrizes da representação - ou multicódigos. Quanto mais operam de forma autoconsciente e autocorretiva, mais aptos estarão seus participantes aí imersos, tanto os viventes quanto os abióticos, para os devires de reabituação que constituem a razoabilidade do universo.

Faremos ao autor apenas um convite para que, em seus futuros textos, nos ajude a entender didaticamente melhor dois aspectos que, neste livro, ainda nos restaram confusos. A primeira dúvida é quando argumenta, no quarto capítulo, a favor do pragmaticismo em comparação ao que chama de "fracassos" explicativos das teorias nominalistas e estruturalistas da comunicologia tradicional: quais fracassos exatamente seriam esses? E por que o pragmaticismo não correria o risco de recair nesses mesmos fracassos? A segunda dúvida é um tanto mais complicada, e diz respeito ao modo como o autor define dedução e indução em suas dimensões de segundeza e terceireza fenomenológicas: enquanto no segundo capítulo afirma que "O mesmo acontece com os outros dois tipos de inferência que descreveremos a seguir, a dedução, com sua predominância de relações de Terceiridade, e a indução, onde predomina a Secundidade" (p. 40); no quarto capítulo escreve que "Para isso é necessário que haja um novo deslocamento desses procedimentos, de forma 
que se efetue a passagem da dominância do primeiro grau de Terceiridade, ou seja, da generalidade da inferência hipotética que consiste na proposta, para particularidades existenciais testáveis, da esfera da Secundidade, por meio da dedução" (p. 138). Ou seja, qual dimensão fenomenológica predomina em cada tipo de raciocínio: a segundeza na dedução e a terceireza da indução, ou vice-versa? E se é a terceireza mais própria da dedução, então por que a ordem da lógica crítica é abdução-dedução-indução, e não abdução-indução-dedução?

Eduardo Fernandes é professor de comunicação visual e projeto gráfico do Curso Superior de Tecnologia em Design Gráfico do IFPE (Instituto Federal de Pernambuco / Campus Recife). É bacharel em Desenho Industrial e Especialista em Tecnologias da Informação pela UFPE; mestre e doutor em Comunicação e Semiótica pela PUCSP. Pesquisador do ESPACC (PUCSP) e vice-líder da linha de pesquisa Linguagem Visual e Design Experimental (IFPE).

dubol@yahoo.com | eduardofernandes@recife.ifpe.edu.br 